UCRL-ID-126989 Rev A

\title{
National Ignition Facility SubSystem Design Requirements Optics Subsystem SSDR 1.6
}

R. Ed English

August 30, 1996

This is an informal report intended primarily for intermal or limited external distribution. The opinions and conclusions atated are those of the author and may or may not be those of the Laboratory.

Work performed under the aupices of the U.S. Department of Energy by the Lawrence Livermore National Laboratory under Contract W-7405-Eng-48. 


\section{DISCLAIMER}

This document was prepared as an account of work sponsored by an agency of the United States Government. Neither the United States Covernment nor the University of California nor any of their employees, makes any warranty, express or implied, or assumes any legal liability or responsibility for the accuracy, completeness, or usefulness of any information, apparatus, product, or process disclosed, or represents that its use would not infringe privately owned rights. Reference herein to any specific commercial product, process, or service by trade name, trademark, manufacturer, or otherwise, does not necessarily constitute or imply its endorsement, recommendation, or favoring by the United States Government or the University of California. The views and opinions of authors expressed herein do not necessarily state or reflect those of the United States Covernment or the University of California, and shall not be used for advertising or product endorsement purposes.

This report has been reproduced directly from the best available copy.

Available to DOE and DOE contractors from the Office of Scientific and Technical Information P.O. Box 62, Oak Ridge, TN 37831

Prices available from (615) 576-8401, FTS 626-8401

Available to the public from the

National Technical Information Service

U.S. Department of Commerce

5285 Port Royal Rd.,

Springfield, VA 22161 


\section{National Ignition Facility \\ Subsystem Design Requirements}

Optics Subsystem

SSDR 1.6

Revision A

August 30, 1996

Prepared by:

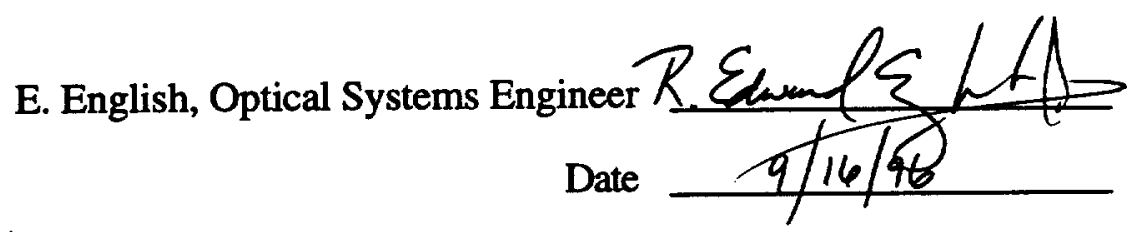

Reviewed:

D. Aikens, Optical Components System Manager

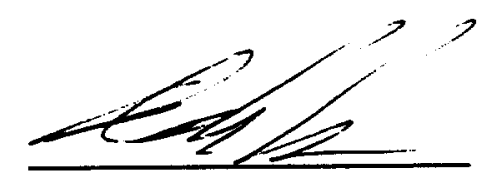

Date

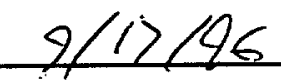

J. Atherton, Laser Material and Optical Technology APL

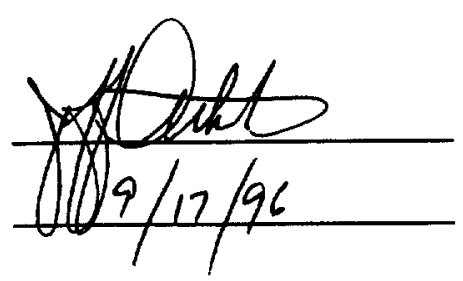

Level 4 Configuration Control Board Approval:

S. Kumpan, NIF Project Engineer S.A. Kumpare Approval Date $10 / 4 / 96$ 


\section{Table of Contents}

\begin{tabular}{|c|c|}
\hline Paragraph & Title \\
\hline 1.0 & $\overline{\text { Scope }}$ \\
\hline 2.0 & Applicable Documents \\
\hline 2.1 & Applicable NIF Documents \\
\hline 2.1 .1 & Applicable NIF Project Documents \\
\hline 2.1 .2 & Applicable NIF Drawings \\
\hline 2.1 .3 & Interface Control Documents \\
\hline 2.2 & Applicable US Goverment Orders, Codes and Standards \\
\hline 2.2 .1 & DOE Orders \\
\hline 2.2 .2 & Other Government Regulations \\
\hline 2.3 & Applicable LLNL Standards \\
\hline 3.0 & Requirements and Verification \\
\hline 3.1 & System Definition \\
\hline 3.1 .1 & System Description \\
\hline 3.1 .2 & System Functions - WBS \\
\hline 3.1 .2 .01 & Laser Slabs (WBS 1.6.1) \\
\hline 3.1 .2 .02 & Lenses (WBS 1.6.2) \\
\hline 3.1 .2 .03 & Mirrors (WBS 1.6.3) \\
\hline 3.1 .2 .04 & Polarizers (WBS 1.6.4) \\
\hline 3.1 .2 .05 & Crystals (WBS 1.6 .5 ) \\
\hline 3.1 .2 .06 & Debris Shields and Windows (WBS 1.6.6) \\
\hline 3.1 .2 .07 & Pulse Generation Optics (WBS 1.6.7) \\
\hline 3.1 .2 .08 & Optical Component Processing (WBS 1.6.8) \\
\hline 3.1 .2 .09 & QA/Damage Testing (WBS 1.6.9) \\
\hline 3.2 & System Characteristics and Verification \\
\hline 3.2 .1 & Performance Characteristics \\
\hline 3.2 .1 .01 & Main and Power Amplifier Slabs - WBS 1.6.1.1/1.6. \\
\hline 3.2 .1 .01 .01 & Thickness \\
\hline 3.2 .1 .01 .02 & Optical Clear Aperture \\
\hline 3.2 .1 .01 .03 & Damage Threshold \\
\hline 3.2 .1 .01 .04 & Wavefront Error - Waviness \\
\hline 3.2 .1 .01 .05 & Transmission \\
\hline 3.2 .1 .01 .06 & Angle of Incidence \\
\hline 3.2 .1 .01 .07 & Nd-doping \\
\hline 3.2 .1 .02 & Cavity Spatial Filter Lens - WBS 1.6.2.1 \\
\hline 3.2 .1 .02 .01 & Optical Clear Aperture \\
\hline 3.2 .1 .02 .02 & Damage Threshold \\
\hline 3.2 .1 .02 .03 & Wavefront Error - Waviness \\
\hline 3.2 .1 .02 .04 & Transmission \\
\hline 3.1 .02 .05 & Cavity Spatial Filter Optical Design \\
\hline 3.2 .1 .02 .06 & Material Stress \\
\hline 3.2 .1 .03 & Transport Spatial Filter Lens (input) - WBS 1.6.2.2 \\
\hline 1.03 .01 & Optical Clear Aperture \\
\hline 1.03 .02 & Damage Threshold \\
\hline 3 & Wavefront Error - Waviness \\
\hline 4 & Transmission \\
\hline 1.03 & Input Transport Spatial Filter Optical Design \\
\hline 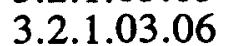 & Stress \\
\hline
\end{tabular}




\section{Table of Contents}

Paragraph

3.2.1.04

3.2.1.04.01

3.2.1.04.02

3.2.1.04.03

3.2.1.04.04

3.2.1.04.05

3.2.1.04.06

3.2.1.05

3.2.1.05.01

3.2.1.05.02

3.2.1.05.03

3.2.1.05.04

3.2.1.05.05

3.2.1.06

3.2.1.06.01

3.2.1.06.02

3.2.1.06.03

3.2.1.06.04

3.2.1.06.05

3.2.1.07

3.2.1.07.01

3.2.1.07.02

3.2.1.07.03

3.2.1.07.04

3.2.1.07.05

3.2.1.08

3.2.1.08.01

3.2.1.08.02

3.2.1.08.03

3.2.1.08.04

3.2.1.08.05

3.2.1.09

3.2.1.09.01

3.2.1.09.02

3.2.1.09.03

3.2.1.09.04

3.2.1.09.05

3.2.1.10

3.2.1.10.01

3.2.1.10.02

3.2.1.11

3.2.1.11.01

3.2.1.11.02

3.2.1.11.03

3.2.1.11.04

3.2.1.11.05
Title

Transport Spatial Filter Lens (output) - WBS 1.6.2.2

Optical Clear Aperture

Damage Threshold

Wavefront Error - Waviness

Reflection

Output Transport Spatial Filter Optical Design

Material Stress

Focus Lens - WBS 1.6.2.3

Optical Clear Aperture

Damage Threshold

Wavefront Error - Waviness

Transmission

Focus Lens Optical Design

Deformable Mirror - WBS 1.6.3.1

Optical Clear Aperture

Damage Threshold

Wavefront Error - Waviness

Reflection

Angle of Incidence

Cavity Mirror - WBS 1.6.3.1

Optical Clear Aperture

Damage Threshold

Wavefront Error - Waviness

Reflection

Angle of Incidence

Elbow Mirror - WBS 1.6.3.2

Optical Clear Aperture

Damage Threshold

Wavefront Error - Waviness

Reflection

Angle of Incidence

Beam Transport Mirrors - WBS 1.6.3.3

Optical Clear Aperture

Damage Threshold

Wavefront Error - Waviness

Reflection

Angle of Incidence

Spatial Filter Injection Mirror - WBS 1.6.3.4

Optical Clear Aperture

Damage Threshold

Polarizer - WBS 1.6.4.1

Optical Clear Aperture

Damage Threshold

Wavefront Error - Waviness

Transmission/Reflection

Angle of Incidence 


\section{Table of Contents}

Paragraph

3.2.1.12

3.2.1.12.01

3.2.1.12.02

3.2.1.12.03

3.2.1.12.04

3.2.1.12.05

3.2.1.12.06

3.2.1.13

3.2.1.13.01

3.2.1.13.02

3.2.1.13.03

3.2.1.13.03

3.2.1.13.05

3.2.1.13.06

3.2.1.13.07

3.2.1.14

3.2.1.14.01

3.2.1.14.02

3.2.1.14.03

3.2.1.14.03

3.2.1.14.05

3.2.1.14.06

3.2.1.14.07

3.2.1.15

3.2.1.15.01

3.2.1.15.02

3.2.1.15.03

3.2.1.15.04

3.2.1.15.05

3.2.1.15.06

3.2.1.16

3.2.1.16.01

3.2.1.16.02

3.2.1.16.03

3.2.1.16.04

3.2.1.16.05

3.2.1.17

3.2.1.17.01

3.2.1.17.02

3.2.1.17.03

3.2.1.17.04

3.2.1.17.05

3.2.1.17.06

3.2.1.18

3.2.1.18.01
Title

Optical Switch Crystal - WBS 1.6.5.1

Optical Clear Aperture

Damage threshold

Wavefront Error - Waviness

Transmission

Angle of Incidence

Orientation

Second Harmonic Generation Crystal - WBS 1.6.5.2

Thickness

Optical Clear Aperture

Damage threshold

Wavefront Error - Waviness

Transmission

Angle of Incidence

Conversion Scheme

Third Harmonic Generation Crystal - 1.6.5.3

Thickness

Optical Clear Aperture

Damage threshold

Wavefront Error - Waviness

Transmission

Angle of Incidence

Conversion scheme

Debris Shield - WBS 1.6.6.1

Optical Clear Aperture

Damage Threshold

Wavefront Error - Waviness

Transmission

Angle of Incidence

Diffractive Structure

Gas Box Window - WBS 1.6.6.2

Optical Clear Aperture

Damage Threshold

Wavefront Error - Waviness

Transmission

Angle of Incidence

Optical Switch Windows - WBS 1.6.6.3

Optical Clear Aperture

Damage Threshold

Wavefront Error - Waviness

Transmission

Angle of Incidence

Material Stress

Transport/Injection Window - WBS 1.6.6.4

Optical Clear Aperture 


\section{Table of Contents}

Paragraph

3.2.1.19

3.2.1.19.01

3.2.1.19.02

3.2.1.19.03

3.2.1.19.04

3.2.1.19.05

3.2.1.19.06

3.2.1.20

3.2.1.20.01

3.2.1.20.02

3.2.1.20.03

3.2.1.20.04

3.2.1.20.05

3.2.1.20.06

3.2.1.20.07

3.2.1.20.08

3.2.1.20.09

3.2.1.21

3.2.1.22

3.2.1.23

3.2.1.23.01

3.2.1.23.02

3.2.1.23.03

4.0

4.1
Title

Target Chamber Vacuum Window - WBS 1.6.6.5

Optical Clear Aperture

Damage Threshold

Wavefront Error - Waviness

Transmission

Angle of Incidence

Material Stress

Diffractive Optics Plate - WBS 1.6.6.6

Optical Clear Aperture

Damage Threshold

Wavefront Error - Waviness

Transmission

Angle of Incidence

Diffractive Structure

Color Separation Grating

Kinoform Phase Plate

Other Uses

Pulse Generation Optics - WBS 1.6.7

Optical Component Processing - WBS 1.6.8

Quality Assurance and Damage Testing - WBS 1.6.9

Interferometry

Photometry

Laser damage testing

Quality Assurance Analysis

Q-Level Assigned 


\section{$1.0 \quad$ Scope}

This Subsystems Design Requirement (SSDR) document specifies the functions to be performed and the subsystems design requirements for the major optical components. These optical components comprise those custom designed and fabricated for amplification and transport of the full aperture NIF beam and does not include those off-the-shelf components that may be part of other optical sub-systems (i.e. alignment or diagnostic systems).

This document also describes the optical component processing requirements and the QA/damage testing necessary to ensure that the optical components meet or exceed the requirements.

\subsection{Applicable Documents}

This section lists DOE orders, codes, and standards which are applicable to the NIF Optics Subsystem Design Requirements. The applicable portions of these documents apply. Applicable LLNL standards are being considered contingent upon the decisions of final site selection.

\subsection{Applicable NIF Documents}

The following NIF Project Documents apply to the Optics Subsystem Design as specifically referenced in later sections.

\subsubsection{Applicable NIF Project Documents}

The following NIF Project Documents shall be applicable to the Optics Subsystem Design:

- National Ignition Facility Functional Requirements and Primary Criteria, Revision 1.4, L-15983-3, February, 1996

- National Ignition Facility System Design Requirements, Laser System SDR002, Revision A, NIFLLNL-96-228, L-21707-01

- "Proposed Metrication Policy for NIF," memo from R. Sawicki, NIF-LLNL-96-038, L-21248-01, 21 January, 1996.

- NIF-LLNL-93-044/L-15958-1, National Ignition Facility Quality Assurance Program Plan, November 1993

- Damage Threshold Requirements for Optics; NIF-LLNL-94-130

\subsubsection{Applicable NIF Drawings}

The following NIF Project drawings apply as specified in Sections 3.1 and 3.2.

AAA96-100596-0B, LTAB NIF Optics Main Laser Optic System

AAA96-104905-00, Target Experimental Systems, General Arrangement, Beam Configuration Layout AAA96-104900-0A, Target Experimental Systems, General Arrangement, FOA-Optics Configuration

\subsubsection{Interface Control Documents}

Interface requirements between WBS level 3 subsystems shall be controlled through separate Interface Control Documents (ICDs).

\subsection{Applicable US Goverment Orders, Codes and Standards}




\subsubsection{DOE Orders}

The following DOE orders are applicable to the Optics Subsystem Design:

DOE 4700.1-Project Management System

DOE 5480.1B - Environmental Protection, Safety, and Health Protection Program for DOE Operations

DOE 5480.4 - DOE Environmental Protection, Safety, and Health Protection Standards

DOE 5480.9-Construction Safety and Health Program

DOE 5480.10-Contractor Industrial Hygiene Program

DOE 5481.1B-Safety Analysis and Review System (for non-nuclear facilities and hazards only)

DOE 5700.6C-Quality Assurance

DOE 6430.1A-General Design Criteria

\subsubsection{Other Government Regulations}

The following Government Regulations are specifically referenced elsewhere in this document and are applicable to the Optics Subsystem Design.

29 CFR 1910-Occupational Safety and Health Act (OSHA)

29 CFR 1910.7 Definitions and Requirements for a Nationally Recognized Testing Laboratory (NRTL) FED-STD-209E-Airborne Particulate Cleanliness Classes in Cleanrooms and Clean Zones

NEPA (National Environmental Policy Act) 42USC 4321 et seq.

California Environmental Quality Act (CEQA)

\subsection{Applicable LLNL Standards}

Pending final site selection, the following LLNL standards generally apply to NIF, and are applicable to the Optics Subsystem Design:

LLNL Committee on Metrification, 10 October 1992, "LLNL Metric Transition Path"

LLNL, M010 "Hazards Control Manual"

LLNL, M-256 "Mechanical Engineering Design Practice"

LLNL "Mechanical Engineering Policy Procedures Manual"

\subsection{Requirements and Verification}

\subsection{System Definition}

The NIF System is designed to support ICF experiments with the goal of fusion ignition. Weapons physics experiments, radiation effects simulation, and other experiments including high energy density science and inertial fusion energy will also be conducted within the capabilities of the system design. The Optics System comprises the special equipment consisting of the laser slabs, lenses, mirrors, polarizers, crystals, debris sheilds and windows, and pulse generation optics. Processes included in the Optics System are cleaning, preassembly, quality assurance, and damage testing.

\subsubsection{System Description}

NIF comprises 192 separate laser beams, each with 39 or 40 components of $400 \mathrm{~mm}$ aperture. The facility will be a large optical system with over 7500 custom designed and fabricated large aperture optical components. The major optical components that comprise the full aperture optics of the NIF beam are listed as follows: 


\section{1. laser slabs}

2. injection, cavity and transport mirrors

3. optical switch crystals and polarizer

4. spatial filter lenses

5. frequency conversion crystals

6. vacuum windows for the Pockels cell

7. focus lens

8. diffractive optics plate/debris shield

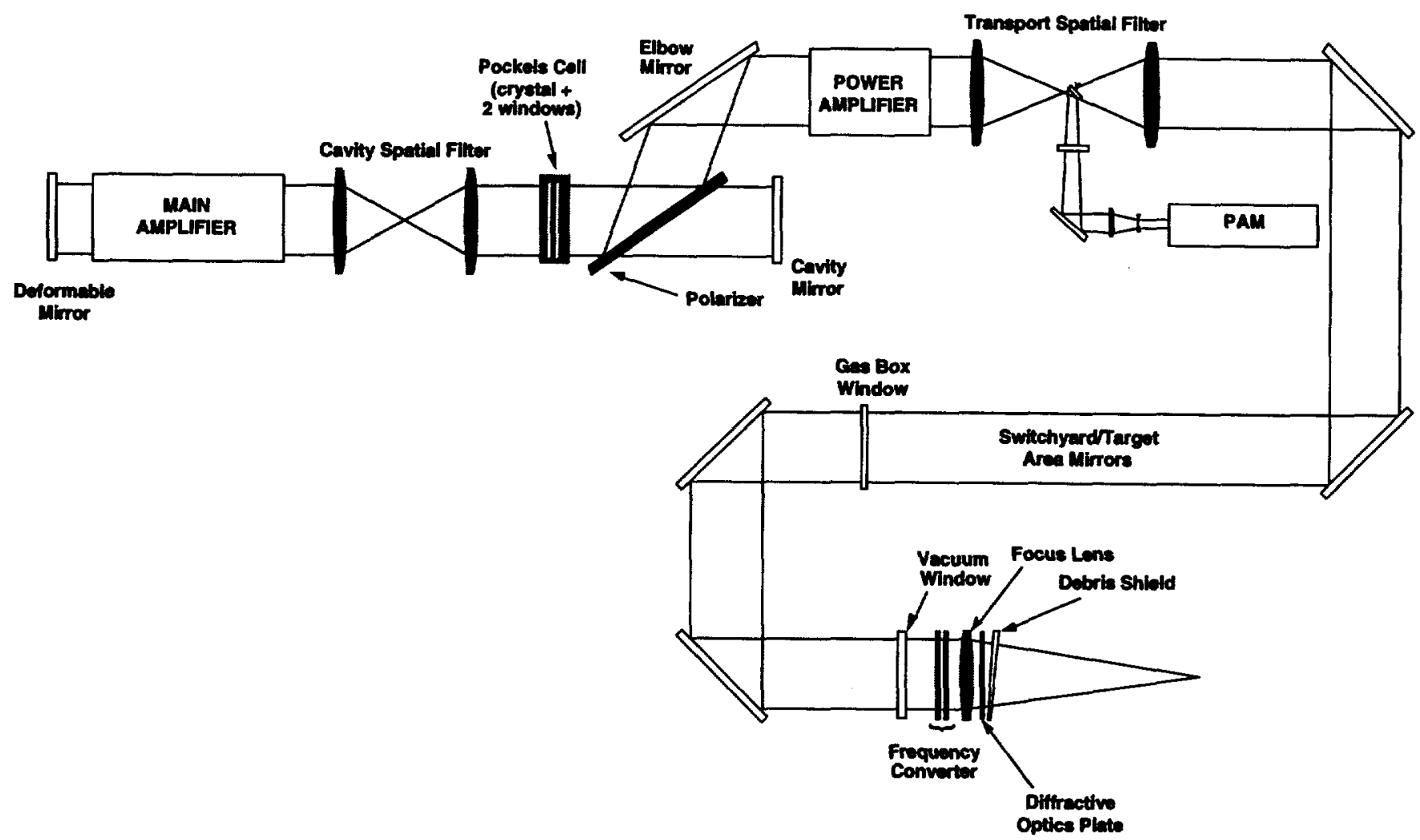

Figure 1 NIF Schematic Optical Layout

The optical path traversed by the pulse from injection in the transport spatial filter, through the multi-pass main cavity to focus on the target is illustrated in Figure 1. The relatively low energy pulse from the preamplifier module (PAM) is transported from the optical pulse generation system, optically matched to the main laser cavity, and injected into the transport spatial filter by a series of small aperture lenses, mirrors, and a transport/injection window. The last mirror in this series, the injection mirror, is located near the spatial filter relay pinhole array. This injection mirror routes the low energy beam from the pre-amplifier through a pinhole in the vacuum spatial filter, through the spatial lens and into the booster or power amplifier. The beam is " $p$ " polarized with respect to the power amplifier slabs The beam passes once through the power amplifier, reflects off of the elbow mirror and reaches the full aperture polarizer in "s" polarization. The polarizer reflects the beam into the main cavity by routing the beam through the Pockels cell.

The beam multi-passes the main amplifier 4 times. After passing through the Pockels cell the first time, the Pockels cell is turned "on". In this state, the Pockels cell rotates the beam $90^{\circ}$ during both the second and third passes. Each time the beam is " $\mathrm{p}$ " polarized with respect to the polarizer and is transmitted 
through it and is reflected by the cavity end mirror. After the third pass through the Pockels cell, the switch is turned "off". The fourth pass of the beam through the Pockels cell results in no rotation. After the fourth pass the beam polarization is " $s$ " with respect to the polarizer and the beam is switched (reflected) out of the main cavity. The beam then reflects off the elbow mirror, passes through the power amplifier and output spatial filter to the transport mirrors and into the final optics.

The final optics consist of vacuum window, frequency conversion crystals, focus lens, diffractive optics plate and debris shield. Frequency conversion occurs in two steps as the beam passes through two nonlinear optical crystals arranged in series. First the $1 \omega$ light is partially converted to the second harmonic, $2 \omega$, in the doubler crystal. Then the $1 \omega$ and $2 \omega$ light are converted to the third harmonic, $3 \omega$, in the tripler crystal. The $3 \omega$ beam is focused onto the target by the focus lens. As the beam converges it passes through the diffractive optics plate, which homogenizes the beam using a phase plate fabricated onto the output surface. Then the beam passes through the final optic, the debris shield. This component protects the focus lens from target debris.

The System Design Requirements for optics damage threshold are a very important parameter in the main laser system design. The values described in this document are the minimum engineering and performance values necessary to support the laser modeling predictions (e.g., Chain-Op). These values are based on several assumptions regarding such things as non-linear index of refraction effects, gain non-uniformity, position in the laser cavity and conversion efficiency. The requirements specified in this document are for beamlets with a $3 \omega$ energy of $9.4 \mathrm{~kJ}$.

\subsubsection{System Functions - WBS}

\subsubsection{Laser Slabs (WBS 1.6.1)}

WBS 1.6.1.1 Cavity amplifier slabs

- gain media for full aperture beam, passed by the extraction beam 4 times

- storage media for flashlamp energy

- edge cladding acts to suppress amplified spontaneous-emission (ASE) that "de-pumps" the slabs

- placed at Brewster's angle to the incident beam, the slabs are natural polarizers that partially reflect "s" polarized light and totally transmit "p" polarized light

WBS 1.6.1.2 Booster amplifier slabs

- gain media for full aperture beam, passed by the extraction beam 2 times

- storage media for flashlamp energy

- edge cladding acts to suppress amplified spontaneous-emission (ASE) that "de-pumps" the slabs

- placed at Brewster's angle to the incident beam, the slabs are natural polarizers that partially reflect "s" polarized light and totally transmit "p" polarized light.

\subsubsection{Lenses (WBS 1.6.2)}

WBS 1.6.2.1 Cavity spatial filter lenses

- collimate beam transmitted through the spatial filter pinhole

- focus return beam from cavity end mirrors through pinhole

- removes spatial beam modulation that accumulates as the cavity beam is amplified

- used in cavity alignment sequence

- AR coated for $1 \omega$ to reduce losses

WBS 1.6.2.2 Transport spatial filter lenses

- collimate portion of beam transmitted through pinhole

- focus beam from elbow mirror through pinhole

- removes spatial beam modulation that accumulates on the beam in the booster amplifier

- used in target alignment sequence 
- AR coated for $1 \omega$ to reduce losses

WBS 1.6.2.3 Focus lens

- focus the collimated $3 \omega$ beam from conversion crystals onto target

- used in target alignment sequence

- AR coated for $3 \omega$ to reduce losses

- has transmission grating for diagnostics on laser side

\subsubsection{Mirrors (WBS 1.6.3)}

WBS 1.6.3.1 Laser cavity end mirrors

WBS 1.6.3.1.1 M1 - Deformable mirror

- high reflector for $1 \omega$, directs cavity beam to second and fourth pinholes

- deformable optic, used to correct for low order static and pump induced wavefront aberrations caused by laser slabs, the Pockels cell, other mirrors and polarizer

- transmitted beam used in cavity alignment sequence

WBS 1.6.3.1.2 M2 - Cavity mirror

- high reflector for $1 \omega$, directs beam through polarizer to third pinhole

- transmission to diagnostic grating for "mid-stage" beam diagnostic station

- used in cavity alignment sequence

WBS 1.6.3.2 M3 - Elbow mirror

- high reflector for $1 \omega$

- directs beam into cavity after injection in the transport spatial filter

- directs output beam into the booster amplifier after "switch-out" by the Pockels cell

- used in alignment sequence

WBS 1.6.3.3 M4-M8 - Beam transport mirrors

- high reflectors for $1 \omega$, direct output beam from the booster amplifier to the final optics assembly

- required for broadband transmitted plasma diagnostic on 16 beamlets

- partial reflector at $3 \omega$ for diagnostics

WBS 1.6.3.4 Spatial filter injection mirror

- high reflector for 10

- directs output of pre-amplifier through pinhole in transport spatial filter

\subsubsection{Polarizers (WBS 1.6.4)}

WBS 1.6.4.1 Optical switch polarizer

- used in alignment of the cavity

- polarizer for $1 \omega$ reflects "s" polarization, transmits "p" polarization

- reflects the injected beam into the main cavity before the Pockels cell is turned "on"

- reflects output beam out of the cavity after Pockels cell is switched "off"

\subsubsection{Crystals (WBS 1.6.5)}

WBS 1.6.5.1 Optical switch crystal

- acts as a optical rotator when an electric field is applied in the direction of beam propagation

- acts as a passive optical element with no electric field applied

- AR coated for $1 \omega$ to reduce losses

WBS 1.6.5.2 Second harmonic generation crystal 
- converts a fraction of the $1 \omega$ beam to $2 \omega$ light

- is AR coated to reduce losses

WBS 1.6.5.3 Third harmonic generation crystal

- converts $1 \omega$ and $2 \omega$ light to $3 \omega$ light

- AR coated to reduce losses

\subsubsection{Debris Shields and Windows (WBS 1.6.6)}

WBS 1.6.6.1 Debris shields

- protects final focus lens from damage from target debris

- AR coated for $3 \omega$ to reduce losses

WBS 1.6.6.2 Gas Box Window

- not part of baseline design; however, it is not precluded

- separates air and noble gas atmospheres used in beam tubes

- AR coated for $1 \omega$ to reduce losses

WBS 1.6.6.3 Optical switch windows

- provides a vacuum barrier for the Pockels cell

- is AR coated for $1 \omega$ to reduce losses and prevent damage from reflections

WBS 1.6.6.4 Transport/Injection Window

- provides vacuum seal for injection into transport spatial filter

- is AR coated for $1 \omega$ to reduce losses

WBS 1.6.6.5 Target Chamber Vacuum Window

- provides vacuum seal for injection into target chamber

- is AR coated for $1 \omega$ to reduce losses

WBS 1.6.6.6 Diffractive Optics Plate

- disperses $1 \omega$ and $2 \omega$ light away from target laser entrance hole

- carries a kinoform phase plate on the output surface to homogenize the beam

- is AR coated for $3 \omega$ to reduce losses

\subsubsection{Pulse Generation Optics (WBS 1.6.7)}

- includes all optical components needed for optical pulse generation system (laser rods, lenses, mirrors, polarizers, Faraday rotators, Pockels cells, wave plates, beam shaping optics, and lens ducts)

\subsubsection{Optical Component Processing (WBS 1.6.8)}

- facilities for cleaning glass and crystal optics

- equipment for cleaning glass and crystal optics

\subsubsection{QA/Damage Testing (WBS 1.6.9)}

- interferometric measurement capability consistent with optics specifications

- photometric measurement capability to evaluate coatings

- laser damage testing equipment to certify damage thresholds and performance

\subsection{System Characteristics and Verification}

\subsubsection{Performance Characteristics}




\subsubsection{Main and Power Amplifier Slabs - WBS 1.6.1.1/1.6.1.2}

\subsection{Thickness}

The thickness of the amplifier slabs shall be $41 \mathrm{~mm}$.

\subsection{Optical Clear Aperture}

The optical clear aperture for the amplifier slabs shall be $400 \mathrm{~mm}$ x $400 \mathrm{~mm}$. The amplifier shall be the limiting aperture in the $1 \omega$ laser.

\subsection{Damage Threshold}

The damage threshold for the amplifier slabs during the delivery of a $2.2 \mathrm{MJ} / 600 \mathrm{TW}$ Haan pulse to the target LEH shall be $>14 \mathrm{~J} / \mathrm{cm} 2$ in the main amplifier and $>22 \mathrm{~J} / \mathrm{cm} 2$ in the power amplifier. This performance shall be verified by testing for a damage threshold of $>19.3 \mathrm{~J} / \mathrm{cm} 2$ for a $3 \mathrm{~ns}, 1064 \mathrm{~nm}$, Gaussian shaped pulse.

\subsection{Wavefront Error - Waviness}

The transmitted wavefront PSD for spatial periods $30 \mathrm{~mm}$ to $0.12 \mathrm{~mm}$ shall be $<1.05 \mathrm{f}^{\wedge}-1.55$, where $P S D$ is in $\mathrm{nm}^{2}-\mathrm{mm}$ and frequency, $\mathrm{f}$, is in $\mathrm{mm}^{-1}$. The transmitted wavefront $\mathrm{rms}$ for spatial periods from $30 \mathrm{~mm}$ to $2.5 \mathrm{~mm}$ shall be $<1.8 \mathrm{~nm}$ and for spatial periods from $2.5 \mathrm{~mm}$ to $0.12 \mathrm{~mm}$ shall be $<1.1 \mathrm{~nm}$.

\subsection{Transmission}

The percent transmission shall be $>99.45 \%$ at $1053 \mathrm{~nm}$.

\subsection{Angle of Incidence}

The angle of incidence for the amplifier slabs shall be Brewster's angle.

\subsection{Nd-doping}

The Nd-doping of the amplifier slabs shall be $3.6( \pm 0.1) \times 10^{\wedge} 20 \mathrm{Nd}+3 / \mathrm{cm} 3$ in order to achieve designed stored energy.

\subsubsection{Cavity Spatial Filter Lens - WBS 1.6.2.1}

\subsection{Optical Clear Aperture}

The optical clear aperture for the cavity SF lens shall be such that the amplifier is the limiting aperture in the $1 \omega$ laser.

\subsection{Damage Threshold}

The damage threshold for the cavity SF lenses during the delivery of a $2.2 \mathrm{MJ} / 600 \mathrm{TW}$ Haan pulse to the target LEH shall be $>14 \mathrm{~J} / \mathrm{cm} 2$. This performance shall be verified by testing for a damage threshold of $>$ $13.0 \mathrm{~J} / \mathrm{cm} 2$ for a $3 \mathrm{~ns}, 1064 \mathrm{~nm}$, Gaussian shaped pulse. 


\subsection{Wavefront Error - Waviness}

The transmitted wavefront PSD for spatial periods $30 \mathrm{~mm}$ to $0.12 \mathrm{~mm}$ shall be $<1.05 \mathrm{f}^{\wedge}-1.55$, where $\mathrm{PSD}$ is in $\mathrm{nm}^{2}-\mathrm{mm}$ and frequency, $\mathrm{f}$, is in $\mathrm{mm}^{-1}$. The transmitted wavefront $\mathrm{rms}$ for spatial periods from $30 \mathrm{~mm}$ to $2.5 \mathrm{~mm}$ shall be $<1.8 \mathrm{~nm}$ and for spatial periods from $2.5 \mathrm{~mm}$ to $0.12 \mathrm{~mm}$ shall be $<1.1 \mathrm{~nm}$.

\subsection{Transmission}

The percent transmission shall be $>99.9 \%$ at $1053 \mathrm{~nm}$ per surface for a new lens.

\subsection{Cavity Spatial Filter Optical Design}

The focal length for the cavity SF lenses shall be chosen to create a one to one image of LM1 onto LM2.

\subsection{Material Stress}

The cavity SF lens shall have a peak stress of $<700$ psi new and 800 psi after refinishing under vacuum load. (Requirement will be changed to 500 psi as part of ECR during Title II.)

\subsubsection{Transport Spatial Filter Lens (input) - WBS 1.6.2.2}

\subsection{Optical Clear Aperture}

The optical clear aperture for the input transport SF lens shall be such that the amplifier is the limiting aperture in the $1 \omega$ laser.

\subsection{Damage Threshold}

The damage threshold for the input transport SF lenses during the delivery of a 2.2 MJ / 600 TW Haan pulse to the target LEH shall be $>23 \mathrm{~J} / \mathrm{cm} 2$. This performance shall be verified by testing for a damage threshold of $>20.8 \mathrm{~J} / \mathrm{cm} 2$ for a $3 \mathrm{~ns}, 1064 \mathrm{~nm}$, Gaussian shaped pulse.

\subsection{Wavefront Error - Waviness}

The transmitted wavefront PSD for spatial periods $30 \mathrm{~mm}$ to $0.12 \mathrm{~mm}$ shall be $<1.05 \mathrm{f}^{\wedge}-1.55$, where $\mathrm{PSD}$ is in $\mathrm{nm}^{2}-\mathrm{mm}$ and frequency, $\mathrm{f}$, is in $\mathrm{mm}^{-1}$. The transmitted wavefront $\mathrm{rms}$ for spatial periods from $30 \mathrm{~mm}$ to $2.5 \mathrm{~mm}$ shall be $<1.8 \mathrm{~nm}$ and for spatial periods from $2.5 \mathrm{~mm}$ to $0.12 \mathrm{~mm}$ shall be $<1.1 \mathrm{~nm}$.

\subsection{Transmission}

The percent transmission shall be $>99.9 \%$ at $1053 \mathrm{~nm}$ per surface for a new lens.

\subsection{Input Transport Spatial Filter Optical Design}

The focal length for the input transport SF lens shall be $30000 \mathrm{~mm}$. The lens shall be designed with a ghost stay-out zone of 0.2 times the focal length.

\subsection{Material Stress}

The input transport SF lens shall have a peak stress of $<700$ psi new and 800 psi after refinishing under vacuum load. (Requirement will be changed to 500 psi as part of ECR during Title II.) 


\subsubsection{Transport Spatial Filter Lens (output) - WBS 1.6.2.2}

\subsection{Optical Clear Aperture}

The optical clear aperture for the output transport SF lens shall be such that the amplifier is the limiting aperture in the $1 \omega$ laser.

\subsection{Damage Threshold}

The damage threshold for the output transport SF lenses during the delivery of a $2.2 \mathrm{MJ} / 600$ TW Haan pulse to the target LEH shall be $>26 \mathrm{~J} / \mathrm{cm} 2$. This performance shall be verified by testing for a damage threshold of $>23.2 \mathrm{~J} / \mathrm{cm} 2$ for a $3 \mathrm{~ns}, 1064 \mathrm{~nm}$, Gaussian shaped pulse.

\subsection{Waviness}

The transmitted wavefront PSD for spatial periods $30 \mathrm{~mm}$ to $0.12 \mathrm{~mm}$ shall be $<1.05 \mathrm{f}^{\wedge}-1.55$, where PSD is in $\mathrm{nm}^{2}-\mathrm{mm}$ and frequency, $\mathrm{f}$, is in $\mathrm{mm}^{-1}$. The transmitted wavefront rms for spatial periods from $30 \mathrm{~mm}$ to $2.5 \mathrm{~mm}$ shall be $<1.8 \mathrm{~nm}$ and for spatial periods from $2.5 \mathrm{~mm}$ to $0.12 \mathrm{~mm}$ shall be $<1.1 \mathrm{~nm}$.

\subsection{Transmission}

The percent transmission shall be $>99.9 \%$ at $1053 \mathrm{~nm}$ per surface for a new lens.

\subsection{Output Transport Spatial Filter Optical Design}

The focal length for the output transport SF lens shall be $30000 \mathrm{~mm}$.

\subsection{Material Stress}

The output transport SF lens shall have a peak stress of $<700$ psi new and 800 psi after refinishing under vacuum load. (Requirement will be changed to 500 psi as part of ECR during Title II.)

\subsubsection{Focus Lens - WBS 1.6.2.3}

\subsection{Optical Clear Aperture}

The optical clear aperture for the final focus lens shall be such that the tripler is the limiting aperture in the final optics.

\subsection{Damage Threshold}

The damage threshold for the final focus lens during the delivery of a $2.2 \mathrm{MJ} / 600$ TW Haan pulse to the target LEH shall be $>13 \mathrm{~J} / \mathrm{cm} 23 \omega$ fluence in the presence of unconverted light. This performance shall be verified by testing for a damage threshold of $>14.1 \mathrm{~J} / \mathrm{cm} 2$ for a $3 \mathrm{~ns}, 355 \mathrm{~nm}$, Gaussian shaped pulse. 


\subsection{Wavefront Error - Waviness}

The transmitted wavefront PSD for spatial periods $30 \mathrm{~mm}$ to $0.12 \mathrm{~mm}$ shall be $<1.05 \mathrm{f}^{\wedge}-1.55$, where PSD is in $\mathrm{nm}^{2}-\mathrm{mm}$ and frequency, $\mathrm{f}$, is in $\mathrm{mm}^{-1}$. The transmitted wavefront $\mathrm{rms}$ for spatial periods from $30 \mathrm{~mm}$ to $2.5 \mathrm{~mm}$ shall be $<1.8 \mathrm{~nm}$ and for spatial periods from $2.5 \mathrm{~mm}$ to $0.12 \mathrm{~mm}$ shall be $<1.1 \mathrm{~nm}$.

\subsection{Transmission}

The percent transmission shall be $>99.8 \%$ at $351 \mathrm{~nm}$ per surface for a new lens.

\subsection{Focus Lens Optical Design}

The focal length for the final focus lens shall be $7000 \mathrm{~mm}$. The lens shall be designed consistent with the unconverted light management strategy.

\subsubsection{Deformable Mirror - WBS 1.6.3.1}

\subsection{Optical Clear Aperture}

The optical clear aperture for the deformable mirror shall be such that the amplifier is the limiting aperture in the $1 \omega$ laser.

\subsection{Damage Threshold}

The damage threshold for the deformable mirror during the delivery of a $2.2 \mathrm{MJ}$ / 600 TW Haan pulse to the target LEH shall be $>3 \mathrm{~J} / \mathrm{cm} 2$. This performance shall be verified by testing for a damage threshold of $>2.6 \mathrm{~J} / \mathrm{cm} 2$ for a $3 \mathrm{~ns}, 1064 \mathrm{~nm}$, Gaussian shaped pulse.

\subsection{Wavefront Error - Waviness}

The reflected wavefront PSD for spatial periods $30 \mathrm{~mm}$ to $0.12 \mathrm{~mm}$ shall be $<1.05 \mathrm{f}^{\wedge}-1.55$, where PSD is in $\mathrm{nm}^{2}-\mathrm{mm}$ and frequency, $\mathrm{f}$, is in $\mathrm{mm}^{-1}$. The reflected wavefront rms for spatial periods from $30 \mathrm{~mm}$ to $2.5 \mathrm{~mm}$ shall be $<1.8 \mathrm{~nm}$ and for spatial periods from $2.5 \mathrm{~mm}$ to $0.12 \mathrm{~mm}$ shall be $<1.1 \mathrm{~nm}$.

\subsection{Reflection}

The percent reflection shall be $>99.5 \%$ at $1053 \mathrm{~nm}$.

\subsection{Angle of Incidence}

The angle of incidence for the deformable mirror shall be $0^{\circ}$.

\subsubsection{Cavity Mirror - WBS 1.6.3.1}

\subsection{Optical Clear Aperture}

The optical clear aperture shall be such that the amplifier is the limiting aperture in the $1 \omega$ laser.

\subsection{Damage Threshold}

The damage threshold for the cavity mirror during the delivery of a $2.2 \mathrm{MJ} / 600 \mathrm{TW}$ Haan pulse to the target LEH shall be $>0.3 \mathrm{~J} / \mathrm{cm} 2$. This performance shall be verified by testing for a damage threshold of $>0.3 \mathrm{~J} / \mathrm{cm} 2$ for a $3 \mathrm{~ns}, 1064 \mathrm{~nm}$, Gaussian shaped pulse. 


\subsection{Wavefront Error - Waviness}

The reflected wavefront PSD for spatial periods $30 \mathrm{~mm}$ to $0.12 \mathrm{~mm}$ shall be $<1.05 \mathrm{f}^{\wedge}-1.55$, where PSD is in $\mathrm{nm}^{2}-\mathrm{mm}$ and frequency, $\mathrm{f}$, is in $\mathrm{mm}^{-1}$. The reflected wavefront $\mathrm{rms}$ for spatial periods from $30 \mathrm{~mm}$ to $2.5 \mathrm{~mm}$ shall be $<1.8 \mathrm{~nm}$ and for spatial periods from $2.5 \mathrm{~mm}$ to $0.12 \mathrm{~mm}$ shall be $<1.1 \mathrm{~nm}$.

\subsection{Reflection}

The percent reflection shall be $>99.5 \%$ at $1053 \mathrm{~nm}$.

\subsection{Angle of Incidence}

The angle of incidence for the cavity mirror shall be $0^{\circ}$.

3.2.1.08 Elbow Mirror - WBS 1.6.3.2

\subsection{Optical Clear Aperture}

The optical clear aperture shall be such that the amplifier is the limiting aperture in the l$\omega$ laser.

\subsection{Damage Threshold}

The damage threshold for the elbow mirror during the delivery of a $2.2 \mathrm{MJ} / 600 \mathrm{TW}$ Haan pulse to the target LEH shall be $>11 \mathrm{~J} / \mathrm{cm} 2$. This performance shall be verified by testing for a damage threshold of $>$ $10.3 \mathrm{~J} / \mathrm{cm} 2$ for a $3 \mathrm{~ns}, 1064 \mathrm{~nm}$, Gaussian shaped pulse.

\subsection{Wavefront Error - Waviness}

The reflected wavefront PSD for spatial periods $30 \mathrm{~mm}$ to $0.12 \mathrm{~mm}$ shall be $<1.05 \mathrm{f}^{\wedge}-1.55$, where PSD is in $\mathrm{nm}^{2}-\mathrm{mm}$ and frequency, $\mathrm{f}$, is in $\mathrm{mm}^{-1}$. The reflected wavefront rms for spatial periods from $30 \mathrm{~mm}$ to $2.5 \mathrm{~mm}$ shall be $<1.8 \mathrm{~nm}$ and for spatial periods from $2.5 \mathrm{~mm}$ to $0.12 \mathrm{~mm}$ shall be $<1.1 \mathrm{~nm}$.

\subsection{Reflection}

The percent reflection shall be $>99.5 \%$ at $1053 \mathrm{~nm}$.

\subsection{Angle of Incidence}

The angle of incidence for the elbow mirror shall be compatible with the polarizer angle of incidence. 3.2.1.09 Beam Transport Mirrors - WBS 1.6.3.3

\subsection{Optical Clear Aperture}

The optical clear aperture for the beam transport mirrors shall be such that the tripler is the limiting aperture in the final optics. The clear aperture shall accommodate pointing within $+/-30 \mathrm{~mm}$ of target chamber center.

\subsection{Damage Threshold}

The damage threshold for the beam transport mirrors during the delivery of a $2.2 \mathrm{MJ} / 600 \mathrm{TW}$ Haan pulse to the target $\mathrm{LEH}$ shall be $>24 \mathrm{~J} / \mathrm{cm} 2$. This performance shall be verified by testing for a damage threshold of $>21.9 \mathrm{~J} / \mathrm{cm} 2$ for a $3 \mathrm{~ns}, 1064 \mathrm{~nm}$, Gaussian shaped pulse. 


\subsection{Wavefront Error - Waviness}

The reflected wavefront PSD for spatial periods $30 \mathrm{~mm}$ to $0.12 \mathrm{~mm}$ shall be $<1.05 \mathrm{f}^{\wedge}-1.55$, where PSD is in $\mathrm{nm}^{2}-\mathrm{mm}$ and frequency, $\mathrm{f}$, is in $\mathrm{mm}^{-1}$. The reflected wavefront $\mathrm{rms}$ for spatial periods from $30 \mathrm{~mm}$ to $2.5 \mathrm{~mm}$ shall be $<1.8 \mathrm{~nm}$ and for spatial periods from $2.5 \mathrm{~mm}$ to $0.12 \mathrm{~mm}$ shall be $<1.1 \mathrm{~nm}$.

\subsection{Reflection}

The percent reflection shall be $>99.5 \%$ at $1053 \mathrm{~nm}$.

\subsection{Angle of Incidence}

The angle of incidence for the beam transport mirror shall be consistent with the beam configuration layout (AAA96-104905).

\subsubsection{Spatial Filter Injection Mirror - WBS 1.6.3.4}

\subsection{Optical Clear Aperture}

The optical clear aperture for the injection mirror shall be such that the amplifier is the limiting aperture in the $1 \omega$ laser.

\subsection{Damage Threshold}

The damage threshold for the injection mirror during the delivery of a $2.2 \mathrm{MJ} / 600 \mathrm{TW}$ Haan pulse to the target LEH shall be $>0.5 \mathrm{~J} / \mathrm{cm} 2$ (The damage threshold of the injection mirror should be high enough to survive spurious back reflections.) This performance shall be verified by testing for a damage threshold of > TBD (8.2) J/cm2 for a $3 \mathrm{~ns}, 1064 \mathrm{~nm}$, Gaussian shaped pulse.

\subsubsection{Polarizer - WBS 1.6.4.1}

\subsection{Optical Clear Aperture}

The optical clear aperture for the polarizer shall be such that the amplifier is the limiting aperture in the $1 \omega$ laser.

\subsection{Damage Threshold}

The damage threshold in reflection for the polarizer during the delivery of a $2.2 \mathrm{MJ} / 600 \mathrm{TW}$ Haan pulse to the target LEH shall be $>11 \mathrm{~J} / \mathrm{cm} 2$ in reflection and $>0.3 \mathrm{~J} / \mathrm{cm} 2$ in transmission. This performance shall be verified by testing for a damage threshold of $>10.5 \mathrm{~J} / \mathrm{cm} 2$ in reflection and $>0.3 \mathrm{~J} / \mathrm{cm} 2$ in transmission for a $3 \mathrm{~ns}, 1064 \mathrm{~nm}$, Gaussian shaped pulse.

\subsection{Wavefront Error - Waviness}

The reflected wavefront PSD for spatial periods $30 \mathrm{~mm}$ to $0.12 \mathrm{~mm}$ shall be $<1.05 \mathrm{f}^{\wedge}-1.55$, where PSD is in $\mathrm{nm}^{2}-\mathrm{mm}$ and frequency, $\mathrm{f}$, is in $\mathrm{mm}^{-1}$. The reflected wavefront rms for spatial periods from $30 \mathrm{~mm}$ to $2.5 \mathrm{~mm}$ shall be $<1.8 \mathrm{~nm}$ and for spatial periods from $2.5 \mathrm{~mm}$ to $0.12 \mathrm{~mm}$ shall be $<1.1 \mathrm{~nm}$. 


\subsection{Transmission/Reflection}

The percent transmission of p-pol shall be $>98 \%$ at $1053 \mathrm{~nm}$ with uniformity of $98 \%$. The percent transmission of s-pol shall be $<1 \%$. The percent reflection of s-pol shall be $>99 \%$ with uniformity of 98\%. The percent reflection of p-pol shall be $<1 \%$.

\subsection{Angle of Incidence}

The angle of incidence for the polarizer shall be $56.43^{\circ} \pm 0.5^{\circ}$, which is Brewster's angle for BK-7. The use angle bandwidth shall be $>1.0^{\circ}$.

\subsubsection{Optical Switch Crystal - WBS 1.6.5.1}

\subsection{Optical Clear Aperture}

The optical clear aperture for the optical switch crystal shall be such that the amplifier is the limiting aperture in the $1 \omega$ laser.

\subsection{Damage threshold}

The damage threshold for the optical switch crystal during the delivery of a $2.2 \mathrm{MJ} / 600 \mathrm{TW}$ Haan pulse to the target $\mathrm{LEH}$ shall be $>13 \mathrm{~J} / \mathrm{cm} 2$. This performance shall be verified by testing for a damage threshold of >11.7 J/cm2 for a $3 \mathrm{~ns}, 1064 \mathrm{~nm}$, Gaussian shaped pulse.

\subsection{Wavefront Error - Waviness}

The transmitted wavefront PSD for spatial periods 33-6, 6-.5, and $.5-.12 \mathrm{~mm}$ shall be $<0.791 \mathrm{f}^{\wedge}-2.701$, 19.008f^-0.927, and 54.911 $\mathrm{f}^{\wedge}-2.457$, where PSD is in $\mathrm{nm}^{2}-\mathrm{mm}$ and frequency, $\mathrm{f}$, is in $\mathrm{mm}^{-1}$. The transmitted wavefront rms for spatial periods $33-6,6-.5$, and $.5-.12 \mathrm{~mm}$ shall be $<9.0 \mathrm{~nm}, 4.2 \mathrm{~nm}$, and $2.0 \mathrm{~nm}$.

\subsection{Transmission}

The percent transmission shall be $>99.8 \%$ at $1053 \mathrm{~nm}$ per surface.

\subsection{Angle of Incidence}

The angle of incidence for the optical switch crystal shall be $0^{\circ}$.

\subsection{Orientation}

The orientation shall be a z-plate with the crystal cut at $0^{\circ}$.

\subsubsection{Second Harmonic Generation Crystal - WBS 1.6.5.2}

\subsection{Thickness}

The thickness of the second harmonic generation crystal shall be $11 \mathrm{~mm}$.

\subsection{Optical Clear Aperture}

The optical clear aperture for the second harmonic generation crystal shall be such that the tripler is the limiting aperture in the final optics. 


\subsection{Damage threshold}

The damage threshold for the second harmonic generation crystal during the delivery of a $2.2 \mathrm{MJ} / 600$ TW Haan pulse to the target LEH shall be $>20.6 \mathrm{~J} / \mathrm{cm} 2$. This performance shall be verified by testing for a damage threshold of $>18.1 \mathrm{~J} / \mathrm{cm} 2$ for a $3 \mathrm{~ns}, 1064 \mathrm{~nm}$, Gaussian shaped pulse.

\subsection{Wavefront Error - Waviness}

The transmitted wavefront PSD for spatial periods $33-6,6-.5$, and $.5-.12 \mathrm{~mm}$ shall be $<0.791 \mathrm{f}^{\wedge}-2.701$, 19.008f^-0.927, and 54.911 $\mathrm{f}^{\wedge}-2.457$, where PSD is in $\mathrm{nm}^{2}-\mathrm{mm}$ and frequency, $\mathrm{f}$, is in $\mathrm{mm}^{-1}$. The transmitted wavefront rms for spatial periods $33-6,6-.5$, and $.5-.12 \mathrm{~mm}$ shall be $<9.0 \mathrm{~nm}, 4.2 \mathrm{~nm}$, and $2.0 \mathrm{~nm}$.

\subsection{Transmission}

The percent transmission shall be $>99.5 \%$ at $1053 \mathrm{~nm}$ per surface.

\subsection{Angle of Incidence}

The angle of incidence for the second harmonic generation crystal shall be $0^{\circ}$.

\subsection{Conversion Scheme}

The conversion scheme shall be Type I doubling with the crystal cut at approximately $41^{\circ}$.

\subsubsection{Third Harmonic Generation Crystal - 1.6.5.3}

\subsection{Thickness}

The thickness of the third harmonic generation crystal shall be $9 \mathrm{~mm}$.

\subsection{Optical Clear Aperture}

The optical clear aperture for the third harmonic generation crystal shall be $400 \mathrm{~mm}$ x $400 \mathrm{~mm}$. The tripler shall be the limiting aperture in the final optics.

\subsection{Damage threshold}

The damage threshold for the third harmonic generation crystal during the delivery of a $2.2 \mathrm{MJ} / 600 \mathrm{TW}$ Haan pulse to the target LEH shall be $>12.6 \mathrm{~J} / \mathrm{cm} 23 \omega$ fluence in the presence of unconverted light. This performance shall be verified by testing for a damage threshold of $>14.3 \mathrm{~J} / \mathrm{cm} 2$ for a $3 \mathrm{~ns}, 355 \mathrm{~nm}$, Gaussian shaped pulse.

\subsection{Wavefront Error - Waviness}

The transmitted wavefront PSD for spatial periods 33-6, 6-.5, and $.5-.12 \mathrm{~mm}$ shall be $<0.791 \mathrm{f}^{\wedge}-2.701$, $19.008 f^{\wedge}-0.927$, and 54.911 $f^{\wedge}-2.457$, where PSD is in $\mathrm{nm}^{2}-\mathrm{mm}$ and frequency, $\mathrm{f}$, is in $\mathrm{mm}^{-1}$. The transmitted wavefront rms for spatial periods $33-6,6-.5$, and $.5-.12 \mathrm{~mm}$ shall be $<9.0 \mathrm{~nm}, 4.2 \mathrm{~nm}$, and $2.0 \mathrm{~nm}$.

\subsection{Transmission}

The percent transmission shall be $>99.5 \%$ at $351 \mathrm{~nm}$ per surface. 


\subsection{Angle of Incidence}

The angle of incidence for the third harmonic generation crystal shall be $0^{\circ}$.

\subsection{Conversion scheme}

The conversion scheme shall be Type II tripling with the crystal cut at approximately $59^{\circ}$.

\subsubsection{Debris Shield - WBS 1.6.6.1}

\subsection{Optical Clear Aperture}

The optical clear aperture for the debris shield shall be such that the tripler is the limiting aperture in the final optics.

\subsection{Damage Threshold}

The damage threshold for the debris shield during the delivery of a 2.2 MJ / 600 TW Haan pulse to the target LEH shall be $>12.4 \mathrm{~J} / \mathrm{cm} 23 \omega$ fluence in the presence of unconverted light. This performance shall be verified by testing for a damage threshold of $>13.7 \mathrm{~J} / \mathrm{cm} 2$ for a $3 \mathrm{~ns}, 1064 \mathrm{~nm}$, Gaussian shaped pulse.

\subsection{Wavefront Error - Waviness}

The debris shield shall not have a transmitted wavefront PSD.

\subsection{Transmission}

The percent transmission shall be $>99.8 \%$ at $351 \mathrm{~nm}$ per surface for a new debris shield. The AR coating should survive shots that produce high $\mathrm{x}$-ray flux (e.g., $0.5 \mathrm{~J} / \mathrm{cm} 2)$.

\subsection{Angle of Incidence}

The angle of incidence for the debris shield shall be according to the ghost reflection analysis.

\subsection{Diffractive Structure}

The debris shield should be capable of having a phase plate and a color separation grating.

\subsubsection{Gas Box Window - WBS 1.6.6.2}

The Gas Box Window is not part of the baseline design; however, it is not precluded.

\subsection{Optical Clear Aperture}

The optical clear aperture for the gas box window shall be such that the tripler is the limiting aperture in the final optics. The clear aperture shall accommodate pointing within $+/-30 \mathrm{~mm}$ of target chamber center.

\subsection{Damage Threshold}

The damage threshold for the gas box window during the delivery of a 2.2 MJ / 600 TW Haan pulse to the target LEH shall be $>22 \mathrm{~J} / \mathrm{cm} 2$. This performance shall be verified by testing for a damage threshold of $>$ $20.0 \mathrm{~J} / \mathrm{cm} 2$ for a $3 \mathrm{~ns}, 1064 \mathrm{~nm}$, Gaussian shaped pulse. 


\subsection{Wavefront Error - Waviness}

The transmitted wavefront PSD for spatial periods $30 \mathrm{~mm}$ to $0.12 \mathrm{~mm}$ shall be $<1.05 \mathrm{f}^{\wedge}-1.55$, where PSD is in $\mathrm{nm}^{2}-\mathrm{mm}$ and frequency, $\mathrm{f}$, is in $\mathrm{mm}^{-1}$. The transmitted wavefront $\mathrm{rms}$ for spatial periods from $30 \mathrm{~mm}$ to $2.5 \mathrm{~mm}$ shall be $<1.8 \mathrm{~nm}$ and for spatial periods from $2.5 \mathrm{~mm}$ to $0.12 \mathrm{~mm}$ shall be $<1.1 \mathrm{~nm}$.

\subsection{Transmission}

The percent transmission shall be $>99.9 \%$ at $1053 \mathrm{~nm}$ per surface.

\subsection{Angle of Incidence}

The angle of incidence for the gas box window shall be $0^{\circ}$.

\subsubsection{Optical Switch Windows - WBS 1.6.6.3}

\subsection{Optical Clear Aperture}

The optical clear aperture for the optical switch window shall be such that the amplifier is the limiting aperture in the $1 \omega$ laser.

\subsection{Damage Threshold}

The damage threshold for the optical switch window during the delivery of a $2.2 \mathrm{MJ} / 600 \mathrm{TW}$ Haan pulse to the target $\mathrm{LEH}$ shall be $>13 \mathrm{~J} / \mathrm{cm} 2$. This performance shall be verified by testing for a damage threshold of $>11.7 \mathrm{~J} / \mathrm{cm} 2$ for a $3 \mathrm{~ns}, 1064 \mathrm{~nm}$, Gaussian shaped pulse.

\subsection{Wavefront Error - Waviness}

The transmitted wavefront PSD for spatial periods $30 \mathrm{~mm}$ to $0.12 \mathrm{~mm}$ shall be $<1.05 \mathrm{f}^{\wedge}-1.55$, where PSD is in $\mathrm{nm}^{2}-\mathrm{mm}$ and frequency, $\mathrm{f}$, is in $\mathrm{mm}^{-1}$. The transmitted wavefront rms for spatial periods from $30 \mathrm{~mm}$ to $2.5 \mathrm{~mm}$ shall be $<1.8 \mathrm{~nm}$ and for spatial periods from $2.5 \mathrm{~mm}$ to $0.12 \mathrm{~mm}$ shall be $<1.1 \mathrm{~nm}$.

\subsection{Transmission}

The percent transmission shall be $>99.9 \%$ at $1053 \mathrm{~nm}$ per surface.

\subsection{Angle of Incidence}

The angle of incidence for the optical switch windows shall be $0^{\circ}$.

\subsection{Material Stress}

The optical switch windows shall have a peak stress of $<700$ psi new and 800 psi after refinishing under vacuum load.

\subsection{3}

\section{Optical Clear Aperture}

The optical clear aperture for the injection window shall be such that the amplifier is the limiting aperture in the $1 \omega$ laser. 


\subsubsection{Target Chamber Vacuum Window - WBS 1.6.6.5}

\subsection{Optical Clear Aperture}

The optical clear aperture shall be such that the tripler is the limiting aperture in the final optics.

\subsection{Damage Threshold}

The damage threshold for the target chamber vacuum window during the delivery of a $2.2 \mathrm{MJ} / 600 \mathrm{TW}$ Haan pulse to the target LEH shall be $>21 \mathrm{~J} / \mathrm{cm} 2$. This performance shall be verified by testing for a damage threshold of $>18.8 \mathrm{~J} / \mathrm{cm} 2$ for a $3 \mathrm{~ns}, 1064 \mathrm{~nm}$, Gaussian shaped pulse. .

\subsection{Wavefront Error - Waviness}

The transmitted wavefront PSD for spatial periods $30 \mathrm{~mm}$ to $0.12 \mathrm{~mm}$ shall be $<1.05 \mathrm{f}^{\wedge}-1.55$, where PSD is in $\mathrm{nm}^{2}-\mathrm{mm}$ and frequency, $\mathrm{f}$, is in $\mathrm{mm}^{-1}$. The transmitted wavefront $\mathrm{rms}$ for spatial periods from $30 \mathrm{~mm}$ to $2.5 \mathrm{~mm}$ shall be $<1.8 \mathrm{~nm}$ and for spatial periods from $2.5 \mathrm{~mm}$ to $0.12 \mathrm{~mm}$ shall be $<1.1 \mathrm{~nm}$.

\subsection{Transmission}

The percent transmission shall be $>99.9 \%$ at $1053 \mathrm{~nm}$ per surface.

\subsection{Angle of Incidence}

The angle of incidence for the target chamber vacuum window shall be according to the ghost reflection analysis.

\subsection{Material Stress}

The target chamber vacuum window shall have a peak stress of $<500$ psi under vacuum load.

\subsubsection{Diffractive Optics Plate - WBS 1.6.6.6}

\subsection{Optical Clear Aperture}

The optical clear aperture for the diffractive optics plate shall be such that the tripler is the limiting aperture in the final optics.

\subsection{Damage Threshold}

The damage threshold for the diffractive optics plate during the delivery of a 2.2 MJ / 600 TW Haan pulse to the target LEH shall be $>13 \mathrm{~J} / \mathrm{cm} 23 \omega$ fluence in the presence of unconverted light. This performance shall be verified by testing for a damage threshold of $>13.9 \mathrm{~J} / \mathrm{cm} 2$ for a $3 \mathrm{~ns}, 1064 \mathrm{~nm}$, Gaussian shaped pulse.

\subsection{Wavefront Error - Waviness}

The diffractive optics plate shall not have a transmitted wavefront PSD.

\subsection{Transmission}

The percent transmission shall be $>99.8 \%$ at $351 \mathrm{~nm}$ per surface. 


\subsection{Angle of Incidence}

The angle of incidence for the diffractive optics plate shall be $0^{\circ}$.

\subsection{Diffractive Structure}

The diffractive optics plate shall have a phase screen for beam smoothing on one side and a color separation grating on the other side.

\subsection{Color Separation Grating}

The color separation grating shall have an efficiency of $>95 \%$ at $3 \omega$ and $<2 \%$ at $1 \omega / 2 \omega$ and should have an efficiency of $>98 \%$ at $3 \omega$ and $<1 \%$ at $1 \omega / 2 \omega$. The grating period shall be chosen consistent with the unconverted light management strategy.

\subsection{Kinoform Phase Plate}

Beam smoothing shall be provided by a kinoform phase screen on one side to produce $0.5 \mathrm{~mm}$ diameter spot (top-hat supergaussian containing $95 \%$ of the energy) at target chamber center.

\subsection{Other Uses}

The diffractive optics plate shall be capable of being produced with different structures to enable other user experiments (e.g., $1 \omega$ shots, specialized beam profiles and positions, diffractive wedges).

\subsubsection{Pulse Generation Optics - WBS 1.6.7}

The optical pulse generation optics shall be designed and specified consistent with the engineering design.

\subsubsection{Optical Component Processing - WBS 1.6.8}

The cleaning and preassembly system shall provide all elements of optical component preassembly, cleaning, and system control.

\subsubsection{Quality Assurance and Damage Testing - WBS 1.6.9}

\subsection{Interferometry}

Interferometry shall be used to provide capability to measure to engineering design requirements. Phase measurements shall be made using phase-shift interferometry to achieve required PV accuracy and gradients.

\subsection{Photometry}

Photometry shall be used to provide capability to measure to engineering design specifications.

\subsection{Laser damage testing}

Laser damage testing shall be used to provide the capability to measure to, and verify, engineering design specifications. 


\subsection{Quality Assurance Analysis}

Quality Assurance for this system will be determined by verification methods identified in Section 3.2.1.23, in combination with the identified Quality Level for individual components.

\subsection{Q-Level Assigned}

\begin{tabular}{|c|c|c|c|c|c|}
\hline \multirow[t]{2}{*}{$\begin{array}{l}\text { WBS } \\
\text { element } \\
\text { number }\end{array}$} & \multirow[t]{2}{*}{ WBS element title } & \multicolumn{3}{|c|}{$\begin{array}{l}\text { Assigned } \\
\text { Q-level }\end{array}$} & \multirow[t]{2}{*}{ Why not Q-level 3 ? } \\
\hline & & 1 & 2 & 3 & \\
\hline$\overline{1.6 .1}$ & amplifier slabs & & & $\sqrt{ }$ & $\begin{array}{l}\text { unique process procedures will be } \\
\text { developed }\end{array}$ \\
\hline 1.6 .2 & lenses & & & & \\
\hline 1.6 .2 .1 & cavity spatial filter (SF 1, 2) & & $\sqrt{ }$ & & $\begin{array}{l}\text { potential safety risk to workers, } \\
\text { process continuity }\end{array}$ \\
\hline 1.6 .2 .2 & transport spatial filter (SF 3, 4) & & $\sqrt{ }$ & & ( \\
\hline 1.6 .2 .3 & final focus & & & $\sqrt{ }$ & \\
\hline & & & & & \\
\hline$\frac{1.0 .3}{1.6 .3 .1}$ & $\begin{array}{l}\text { mirrors } \\
\text { cavity mirrors }\end{array}$ & & & & \\
\hline 1.6 .3 .1 .1 & cavity end mirror $\quad$ (M2) & & & $\sqrt{ }$ & \\
\hline 1.6 .3 .1 .2 & deformable mirror $\quad$ (M1) & & $\sqrt{ }$ & & $\begin{array}{l}\text { design unique to NIF, unplanned } \\
\text { maintenance may affect } \\
\text { performance }\end{array}$ \\
\hline 1.6 .3 .2 & optical switch (elbow) mirror (M3) & & & $\sqrt{ }$ & \\
\hline 1.6 .3 .3 & beam transport mirrors & & & $\sqrt{ }$ & \\
\hline 1.6 .3 .4 & spatial filter injection mirrors & & & & $\begin{array}{l}\text { considered part of pulse } \\
\text { generation optics } 1.6 .7 . \mathrm{X}\end{array}$ \\
\hline 1.6 .4 & polarizers & & & & \\
\hline$\overline{1.6 .4 .1}$ & optical switch polarizer & & & $\sqrt{ }$ & \\
\hline $\mathbf{1 . 6 . 5}$ & KDP and $\mathrm{KD}^{*} \mathrm{P}$ crystals & & & $\sqrt{ }$ & $\begin{array}{l}\text { unique process procedures will be } \\
\text { developed }\end{array}$ \\
\hline 1.6 .5 .1 & optical switch & 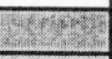 & 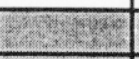 & $x^{2}$ & 20 \\
\hline 1.6 .5 .2 & second harmonic generation & 3 & $\operatorname{lin}^{2}$ & 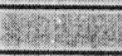 & 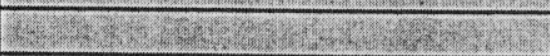 \\
\hline 1.6 .5 .3 & third harmonic generation & 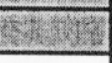 & - & $\sqrt{3 \sqrt{252}}$ & 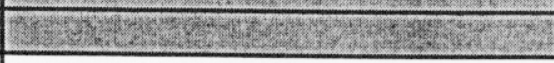 \\
\hline 1.6 .6 & debris shields and windows & & & & \\
\hline 1.6 .6 .1 & debris shields & & & $\sqrt{ }$ & $\begin{array}{l}\text { coating, measurement and } \\
\text { cleaning process procedures will } \\
\text { be developed which are unique } \\
\text { to these optical components. }\end{array}$ \\
\hline
\end{tabular}




\begin{tabular}{|c|c|c|c|c|c|}
\hline$\overline{1.6 .6 .2}$ & gas box windows & & & $\sqrt{ }$ & \\
\hline$\overline{1.6 .6 .3}$ & optical switch windows & & & $\sqrt{ }$ & \\
\hline$\overline{1.6 .6 .4}$ & transport/injection window & & & $\sqrt{ }$ & \\
\hline$\overline{1.6 .6 .5}$ & target chamber vacuum window & & $\sqrt{ }$ & & $\begin{array}{l}\text { potential environmental and } \\
\text { safety impact, } \\
\text { long schedule delay }\end{array}$ \\
\hline$\overline{1.6 .6 .6}$ & diffractive optics plate & & & $\sqrt{ }$ & $\begin{array}{l}\text { coating, measurement and } \\
\text { cleaning process procedures will } \\
\text { be developed which are unique } \\
\text { to these optical components. }\end{array}$ \\
\hline L.6.7 & pulse generation optics & & & & \\
\hline & & & & & \\
\hline 1.6 .8 & optical component processing & $\begin{array}{l}\text { not app } \\
\text { carry Q }\end{array}$ & $\begin{array}{l}\text { licable, } 0 \\
\text {-level of }\end{array}$ & $\begin{array}{l}\text { ptical cor } \\
\text { the optic }\end{array}$ & $\begin{array}{l}\text { mponent processing tasks will } \\
\text { al component involved. }\end{array}$ \\
\hline L.6.8.1 & $\begin{array}{l}\text { Optical Component Receiving and } \\
\text { Inspection }\end{array}$ & & & & 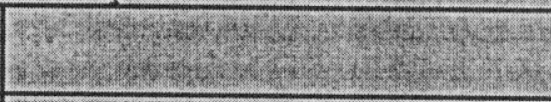 \\
\hline .6.8.1.1 & Processing QA & 4 & \begin{tabular}{|c|}
$\cos 40$ \\
\end{tabular} & \begin{tabular}{r|r|} 
\\
\end{tabular} & 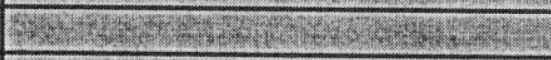 \\
\hline .6 .8 .1 .2 & Inspection & $\sqrt{4 x+8}$ & 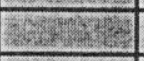 & \begin{tabular}{|l|l|}
$20-9$ \\
\end{tabular} & 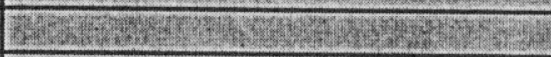 \\
\hline .6 .8 .1 .3 & Tracking and Inventory & $\operatorname{lin}_{15}$ & 12:0 & 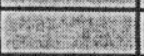 & 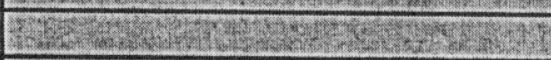 \\
\hline .6 .8 .3 .4 & Storage & (5) & - & \begin{tabular}{|l|l|}
$x+20$ \\
\end{tabular} & 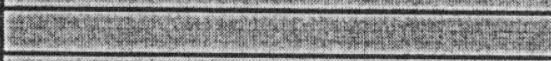 \\
\hline .6 .8 .2 & Optical Component Cleaning & 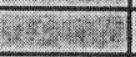 & 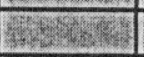 & 5 & 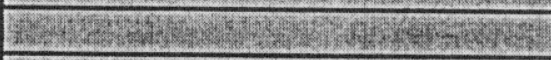 \\
\hline .6 .8 .2 .1 & Requirements & 8 & 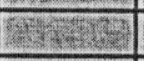 & 8 & 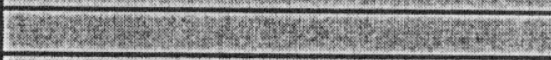 \\
\hline .6 .8 .2 .2 & Mechanical Cleaning & 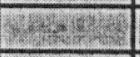 & \begin{tabular}{|c|}
$x-5$ \\
\end{tabular} & 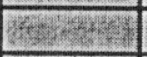 & 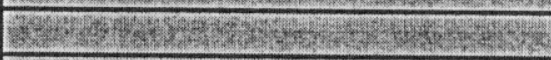 \\
\hline .6 .8 .2 .3 & Precision Optics Cleaning & 20 & 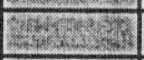 & $2 \sqrt{2 x}$ & 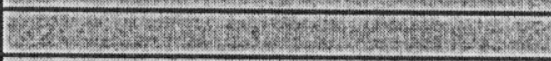 \\
\hline .6 .8 .2 .4 & Pre-assembly Cleaning & 5 & 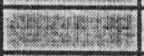 & 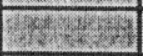 & 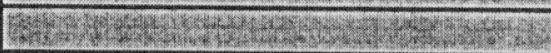 \\
\hline .6 .8 .3 & Sol gel Coating & 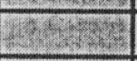 & Crestat & \begin{tabular}{|l|}
-9 \\
\end{tabular} & 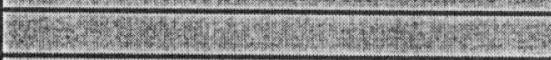 \\
\hline .6 .8 .3 .1 & Anti-reflective Sol gel Coating & Exing & एक्य & 24ing & 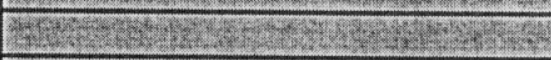 \\
\hline .6 .8 .3 .2 & High-reflective Sol gel Coating & क्षित्र & Fingerses & 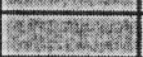 & 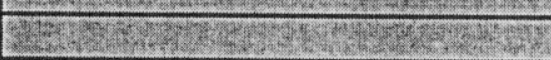 \\
\hline .6 .8 .3 .3 & $\begin{array}{l}\text { KDP / KD*P Anti-reflective Sol gel } \\
\text { Coating }\end{array}$ & & & & \\
\hline .6 .8 .4 & $\begin{array}{l}\text { Optical Component } \\
\text { Assembly/Packaging and Handling } \\
\text { Systems }\end{array}$ & & & & \\
\hline .6 .9 & QA and damage testing & $\begin{array}{l}\text { not app } \\
\text { level of }\end{array}$ & $\begin{array}{l}\text { licable, } \\
\text { the optic }\end{array}$ & $\begin{array}{l}2 \mathrm{~A} \text { and } \mathrm{d} \\
\text { cal compc }\end{array}$ & $\begin{array}{l}\text { amage testing tasks will carry } \mathrm{Q}^{-} \\
\text {onent involved. }\end{array}$ \\
\hline .6 .9 .1 & $\begin{array}{l}\text { Test Planning and Training } \\
\text { Procedures }\end{array}$ & & & & \\
\hline .6 .9 .2 & Metrology & 2 & \begin{tabular}{|l|l|}
$\sin$ \\
\end{tabular} & 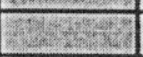 & 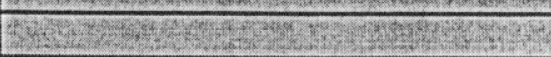 \\
\hline .6 .9 .2 .1 & Photometry & $6=2$ & \begin{tabular}{|l|}
$x+2,20$ \\
\end{tabular} & \begin{tabular}{|l|}
-2 \\
\end{tabular} & 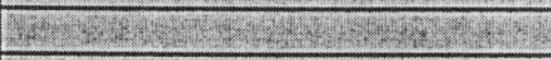 \\
\hline .6 .9 .2 .2 & Interferometry & - & 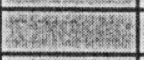 & 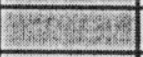 & 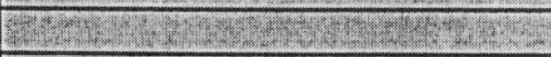 \\
\hline .6 .9 .2 .3 & Other & 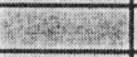 & \begin{tabular}{|c|c|}
$\sin$ \\
\end{tabular} & 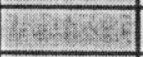 & 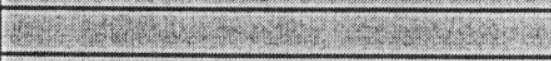 \\
\hline .6 .9 .3 & Laser Damage & 5 & \begin{tabular}{|c|} 
\\
\end{tabular} & - & 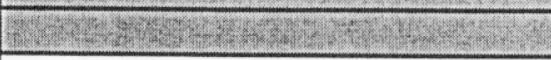 \\
\hline.$\overline{6.10}$ & optical component integration & \multicolumn{4}{|c|}{$\begin{array}{l}\text { not applicable, integration tasks will carry Q-level of the } \\
\text { optical component involved. }\end{array}$} \\
\hline .6 .10 .1 & optical design integration & Esing & \begin{tabular}{|l|l|}
-2.96 \\
\end{tabular} & & 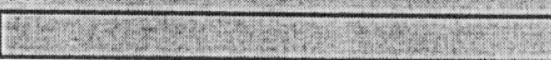 \\
\hline
\end{tabular}




\begin{tabular}{|l|l|l|l|l|l|}
\hline 1.6.10.1.1 & Project Management and Planning & & & & \\
\hline 1.6 .10 .1 .2 & Optical System Design & & & & \\
\hline 1.6 .10 .1 .3 & Laser System Design & & & & \\
\hline 1.6 .10 .1 .4 & Beam Transport System Design & & & & \\
\hline 1.6 .10 .1 .5 & Systems Control Design & & & & \\
\hline 1.6 .10 .1 .6 & Target Experimental System Design & & & & \\
\hline 1.6 .10 .1 .7 & Optical Specifications & & & & \\
\hline 1.6 .10 .1 .8 & Components Integration & & & & \\
\hline 1.6 .10 .2 & Optical Process Integration & & & & \\
\hline 1.6 .10 .2 .1 & Project Management and Planning & & & & \\
\hline 1.6 .10 .2 .2 & $\begin{array}{l}\text { Reliability / Availability / } \\
\text { Maintainability }\end{array}$ & & & & \\
\hline 1.6 .10 .2 .3 & Requirements / Interface Control & & & & \\
\hline 1.6 .10 .2 .4 & System Engineering & & & & \\
\hline
\end{tabular}

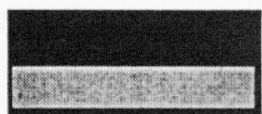

$=$ not evaluated at this level, analysis at lower WBS level

$=$ not applicable, either analyzed at a higher level or analysis postponed until Title II

\subsection{Revision Record}

\begin{tabular}{|l|l|l|l|l|}
\hline Rev & Date & ECR\# & By & Description of/Reason for Change \\
\hline 0 & CDR & n/a & & \\
\hline A & $10 / 6 / 96$ & 58 & English & Title I issue, reworked and reformatted from CDR SDR005 \\
\hline & & & & \\
\hline
\end{tabular}




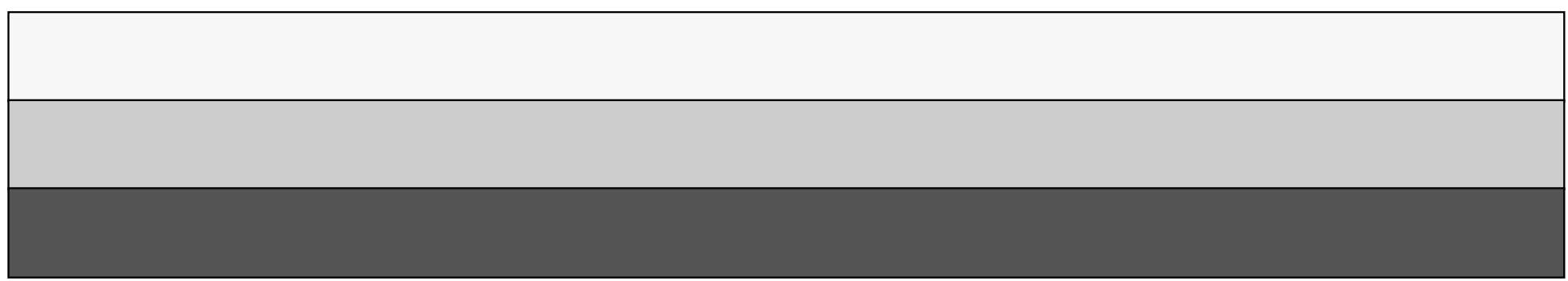

